ГЕНЕТИЧЕСКИЙ ПОЛИМОРФИЗМ ВОЗБУДИТЕЛЯ

ТУБЕРКУЛЕЗА НА ТЕРРИТОРИИ ГОРОДА С ОГРАНИЧЕННОЙ МИГРАЦИЕЙ НАСЕЛЕНИЯ И ВЫСОКИМ УРОВНЕМ ЗАБОЛЕВАЕМОСТИ ВИЧ-ИНФЕКЦИЕЙ

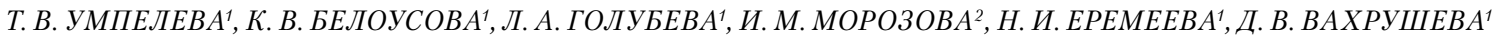

'ФГБУ «Национальный медицинский исследовательский центр фтизиопульмонологии и инфекционных заболеваний» МЗ РФ, г. Екатеринбург, РФ

${ }^{2}$ ФГБУЗ «ЦМСЧ № 31 ФМБА России», г. Новоуральск, РФ

Проведено исследование 87 изолятов M. tuberculosis, выделенных от больных туберкулезом жителей Новоуральского городского округа в 2013-2016 гг. Выявлен высокий процент изолятов, обладающих множественной лекарственной устойчивостью: 66 и 85,3\% среди впервые выявленных и ранее леченных больных соответственно. Генотипирование позволило установить доминирование изолятов группы Веіјіп как среди впервые выявленных (75,5\%), так и среди ранее леченных больных (85,3\%), при этом 52,8 и $67,6 \%$ изолятов соответственно принадлежали варианту Beijing B0/W148. MIRU-VNTR-типирование позволило выявить девять изолятов группы Веijing B0/W148 с нетипичным числом повторов в локусе QUB26 (два). В работе отмечен высокий процент больных туберкулезом с ВИЧ-инфекцией (39,1\%), при этом в группах больных туберкулезом с различным ВИЧ-статусом отличий в доле возбудителя с множественной лекарственной устойчивостью и принадлежностью к генотипу Beijing (ВеijingB0/W148) не выявлено. Показана возможность использования технологий генотипирования для подтверждения/опровержения эпидемических связей между пациентами и поиска ранее неизвестных механизмов передачи туберкулезной инфекции.

Ключевые слова: M. tuberculosis, генотипирование, Новоуральск, лекарственная устойчивость, Веijing, ВИЧ-инфекция

Для цитирования: Умпелева Т. В., Белоусова К. В., Голубева Л. А., Морозова И. М., Еремеева Н. И., Вахрушева Д. В. Генетический полиморфизм возбудителя туберкулеза на территории города с ограниченной миграцией населения и высоким уровнем заболеваемости ВИЧ-инфекцией // Туберкулёз и болезни лёгких. - 2019. - Т. 97, № 3. - C. 40-45. http://doi.org/10.21292/2075-1230-2019-97-3-40-45

\title{
GENETIC POLYMORPHISM OF TUBERCULOSIS MYCOBACTERIA IN THE CITY WITH LIMITED POPULATION MIGRATION AND HIGH INCIDENCE OF HIV INFECTION
}

\author{
T. V. UMPELEVA', K. V. BELOUSOVA', L. A. GOLUBEVA', I. M. MOROZOVA' , N. I. EREMEEVA ${ }^{1}$, D. V. VAKHRUSHEVA
}

${ }^{1}$ National Medical Research Center of Phthisiopulmonology and Infectious Diseases, Yekaterinburg, Russia

${ }^{2}$ Central Medical Sanitary Unit no. 31 by the Russian Federal Medical Biological Agency, Novouralsk, Russia

87 isolates of M. tuberculosis isolated from tuberculosis patients in the Novouralsk municipality in 2013-2016 were studied. It was found out that a high percentage of isolates had multiple drug resistance: 66 and 85.3\% among newly diagnosed and previously treated patients, respectively. Genotyping allowed revealing the dominance of isolates of the Beijing family, both among newly diagnosed (75.5\%) and previously treated patients (85.3\%), with 52.8 and $67.6 \%$ of isolates, respectively, belonging to the Beijing B0/W148 variant. MIRU-VNTR-typing detected nine isolates of the Beijing B0/W148 family with an atypical number of repeats in the QUB26 locus (two). A high rate of tuberculosis with concurrent HIV (39.1\%) was noted, while in groups of tuberculosis patients with various HIV statuses, no difference was detected in the ratio of multiple drug resistant pathogens and belonging to the Beijing genotype (BeijingB0/W148). The article demonstrates the possibility of using genotyping technologies to confirm/deny the epidemiological relationship between patients and search for previously unknown mechanisms of tuberculosis infection transmission. Key words: M. tuberculosis, genotyping, Novouralsk, drug resistance, Beijing, HIV infection

For citations: Umpeleva T.V., Belousova K.V., Golubeva L.A., Morozova I.M., Eremeeva N.I., Vakhrusheva D.V. Genetic polymorphism of tuberculosis mycobacteria in the city with a limited population migration and high incidence of HIV infection. Tuberculosis and Lung Diseases, 2019, Vol. 97, no. 3, P. 40-45. (In Russ.) http://doi.org/10.21292/2075-1230-2019-97-3-40-45

Новоуральск - один из закрытых городов атомной промышленности - был основан в 1941 г. в юго-западной части Свердловской области. С 2006 г. муниципальное образование город Новоуральск было преобразовано в Новоуральский городской округ, объединяющий, помимо закрытого города, еще пять населенных пунктов [4, 7]. Учитывая условия ограниченной миграции населения, такой город в определенной мере может служить моделью формирования и распространения новых форм возбудителей инфекционных заболеваний, в том числе туберкулеза, на закрытой территории. За последние годы показатель заболеваемости туберкулезом в Новоуральском городском округе имеет тенденцию к снижению $(61,5 / 100$ тыс. в 2013 г., 47,17/100 тыс. в 2017 г.), однако отмечается высокий показатель заболеваемости среди сельского населения (108,6/100 тыс. в 2017 г.). Одним из отягощающих факторов распространения туберкулезной инфекции является высокий показатель распространения ВИЧ-инфекции среди населения (1 432,2/100 тыс. в 2017 г.). Доля ВИЧ-позитивных лиц среди всех впервые выявленных больных туберкулезом в 2017 г. составила 29,5\% [5].

Цель исследования: изучить структуру популяции Mycobacterium tuberculosis на территории Ново- 
уральского городского округа, выявить эпидемически значимые варианты возбудителя туберкулеза и изучить влияние ВИЧ-инфекции на их распространение.

\section{Материалы и методы}

В 2013-2016 гг. в лаборатории микробиологии и ПЦР-диагностики Уральского НИИ фтизиопульмонологии (филиал ФГБУ «НМИЦ ФПИ» Минздрава России) был выделен 181 изолят M. tuberculosis от 118 больных туберкулезом жителей Новоуральского городского округа. В исследование было включено 87 образцов - впервые полученные изоляты от 87 пациентов, у которых были известны данные из историй болезни. Мужчин было 69 (79,3\%), женщин - 18 (20,7\%). Согласно данным из историй болезни, 34 (39,1\%) пациента выборки были ВИЧ-позитивными. 53 (60,1\%) пациента вошли в группу впервые выявленных больных (диагноз туберкулеза установлен впервые), 34 (39,9\%) в группу ранее леченных (диагноз туберкулез был установлен более года назад).

Культуры микобактерий были получены из клинического материала пациентов на плотной питательной среде Левенштейна - Йенсена [11]. Лекарственную чувствительность возбудителя туберкулеза определяли методом абсолютных концентраций [11]. По 1 мл суспензии микобактерий, оставшейся после постановки теста на лекарственную чувствительность, в течение 2013-2016 гг. сохраняли в криопробирках с 20\% глицерина при минус $80^{\circ} \mathrm{C}$. Выделение ДНК проводили из размороженной суспензии микобактерий с использованием набора реагентов «Экспресс-туб» (НПК Синтол, г. Москва), предварительно отмыв осадок клеток ddH $\mathrm{H}_{2} \mathrm{O}$. Принадлежность к генотипу Beijing определяли тест-системой «Амплитуб-Beijing» (НПК Синтол, Москва), принадлежность к кластеру Beijing B0/W148 - мультиплексной ПЦР. Bce изоляты генотипа Beijing были дополнительно генотипированы по двум наиболее полиморфным для этой генетической группы локусам: MIRU26, QUB26. Изоляты, принадлежащие к другим генетическим линиям (non-Beijing), были генотипированы и классифицированы с использованием набора «Сполигочип» (ИМБ-БИОЧИП, г. Москва). Для девяти изолятов выявляли мутации устойчивости к противотуберкулезным препаратам с использованием тест-системы «ТБ-ТЕСТ» (ИМБ-БИОЧИП, г. Москва).

Статистический анализ проводили с использованием таблиц сопряженности и критерия хи-квадрат $\left(\chi^{2}\right)$; статистически значимыми считали различия при $p<0,05$.

\section{Результаты исследования}

Оценка доли пациентов с сочетанием инфекций - ВИЧ-инфекция и туберкулез (ВИЧ-и/ТБ) в половых группах выявила более высокий показатель среди женщин $(61,1 \%)$, нежели среди мужчин $(33,3 \%)$, разница статистически не значима $(p=0,06)$, так же как среди впервые выявленных $(37,7 \%)$ и ранее леченных $(41,1 \%)$ больных туберкулезом (табл. 1).

Множественная лекарственная устойчивость (МЛУ) микобактерий туберкулеза (МБТ) была выявлена у 35 (66\%) впервые выявленных больных, данный показатель оказался почти на $22 \%$ выше, чем в среднем по Свердловской области (43,9\%) за 2015-2016 гг. $(p<0,05)$ [6]. Среди ранее леченных больных доля пациентов с МЛУ МБТ составила 85,3\%. Доля лекарственно-чувствительных изолятов МБТ составила 28,3\% среди впервые выявленных и 2,9\% среди ранее леченных больных.

Среди впервые выявленных больных туберкулезом ВИЧ-позитивных и ВИЧ-негативных доля МЛУ-ТБ составила 65 и 66,5\% соответственно (табл. 1), что не имело статистически значимых различий. Ранее другими исследователями для Свердловской области было показано, что изоляты МЛУ МБТ у больных с сочетанием ВИЧ-и/ТБ выделяли достоверно чаще (50,30\%), чем среди ВИЧ-негативных больных туберкулезом (31,33\%) $(p<0,01)$ [9].

Генотипирование возбудителя туберкулеза выявило доминирование изолятов генотипа Beijing как среди впервые выявленных больных (75,5\%), так и среди ранее леченных (85,3\%). Принадлежали к эпидемически и клинически значимому для России варианту Beijing B0/W148 52,8 и 67,6\% изолятов МБТ, выделенных от впервые выявленных и ранее леченных больных соответственно, что существенно превышало этот показатель на других территориях России [1-3]. Согласно опубликованным данным по Уральскому федеральному округу [10], доля изо-

Таблица 1. Характеристика больных туберкулезом с различным ВИЧ-статусом и выделенные от них изоляты МБТ Table 1. Characteristics of tuberculosis patients with different HIV status and MTB isolated in them

\begin{tabular}{|l|c|c|c|c|c|c|}
\hline ВИЧ-статус & $\begin{array}{c}\text { Число больных } \\
\text { абс.(\%) }\end{array}$ & $\begin{array}{c}\text { Женщины/ мужчины } \\
\text { абс.(\%) }\end{array}$ & ВВ/РЛ абс.(\%) & $\begin{array}{c}\text { МлУ МБТ ВВ/Pл } \\
\text { абс.(\%) }\end{array}$ & $\begin{array}{c}\text { Вeijing ВВ/PЛ } \\
\text { абс.(\%) }\end{array}$ & $\begin{array}{c}\text { ВеijingВ0 ВВ/PЛ } \\
\text { абс.(\%) }\end{array}$ \\
\hline ВИЧ+ & $34(39,1 \%)$ & $11(61,1 \%) / 23(33,3 \%)$ & $20(37,7 \%) / 14(41,2 \%)$ & $13(65 \%) / 11(78,5 \%)$ & $18(90 \%) / 13(92,8 \%)$ & $11(55 \%) / 10(71,4 \%)$ \\
\hline ВИЧ- & $53(60,9 \%)$ & $7(38,9 \%) / 46(66,7 \%)$ & $33(62,3 \%) / 20(58,8 \%)$ & $22(66,6 \%) / 18(90 \%)$ & $22(66,7 \%) / 16(80 \%)$ & $17(51,5 \%) / 13(65 \%)$ \\
\hline Всего & 87 & $18(20,7 \%) / 69(79,3 \%)$ & $53(60,9 \%) / 34(39,1 \%)$ & $35(66 \%) / 29(85,3 \%)$ & $40(75,5 \%) / 29(85,3)$ & $28(52,8 \%) / 23(67,6 \%)$ \\
\hline
\end{tabular}

Примечание: ВВ - впервые выявленные больные туберкулезом; Рл - ранее леченные больные туберкулезом 
лятов генетической группы Beijing в 2009-2011 гг. среди впервые выявленных больных составляла $55,1 \%$, что на 20,4\% ниже, чем в исследованной нами выборке $(p<0,05)$. У больных с ВИЧ-и/ТБ доля изолятов Beijing/Beijing B0/W148 составила 91,2/61,7\% и была несколько выше, чем среди больных туберкулезом ВИЧ-негативных (73,5/56,6\%), однако эти отличия были статистически не значимы. Ранее другими исследователями было показано, что на территории Свердловской области изоляты Beijing достоверно чаще встречались у больных с ВИЧ-и/ТБ [9].

При сопоставлении результатов определения лекарственной чувствительности и генотипа возбудителей установлено, что 86,7\% изолятов МБТ группы Beijing обладали МЛУ, были полирезистентны 5,8\%, только 7,3\% были лекарственно-чувствительными. При этом в кластере Beijing B0/W148 выявлены только изоляты с МЛУ/ШЛУ - 94,1/11,8\% и полирезистентные бактерии - 5,9\%. Напротив, 64,7\% изолятов МБТ группы non-Beijing были лекарственно-чувствительными, 5,9\% - полирезистентными, а 29,4\% обладали МЛУ (табл. 2).

Сполиготипирование позволило разбить группу non-Beijing на девять типов, самый многочисленный - SIT35 (Ural) - объединял 7 изолятов, по 2 изолята принадлежали сполиготипам SIT262 и SIT254, по 1 изоляту - SIT42, SIT53, SIT182, SIT252, SIT334, SIT402.

MIRU-VNTR-типирование изолятов группы Beijing по двум локусам (MIRU26, QUB26) позволило выделить девять кластеров (табл. 2). Самый крупный из них объединял 32 изолята и характеризовался семью повторами в обоих локусах.
Интересно отметить кластер из 9 изолятов, имеющих нетипичное для Beijing B0/W148 число повторов в локусе QUB26 - два повтора. Ранее было описано, что для представителей данного кластера характерно 6-7 повторов в локусе QUB26 [12]. Высокая доля изолятов Beijing B0/W148 с таким набором повторов (2 QUB26, 7 MIRU26) (10,3\%) в исследованной выборке позволяет предположить, что данный клональный вариант возбудителя мог возникнуть на территории Новоуральского городского округа и начать успешно распространяться на закрытой территории, пока широко не выходя за его пределы.

В дополнение к данным генотипирования для МБТ впервые выделенного нами кластера Beijing B0/W148 (2 QUB26, 7 MIRU26) проведено изучение мутаций, ассоциированных с лекарственной устойчивостью, которое выявило сходный профиль мутаций для всех 9 изолятов этой группы по четырем противотуберкулезным препаратам: изониазид (kat $G$ Ser315Thr(1); рифампицин (rpoB Ser531Leu); этамбутол (embB M306V); аминогликозиды (eis g10a). Не содержали мутаций, ассоциированных с устойчивостью к фторхинолонам, 8 из 9 изолятов этой группы, в 1 случае выявлена такая мутация (gyrA A90V). Следует отметить, что методом абсолютных концентраций только для 2 изолятов этой группы выявлена устойчивость к этамбутолу, для 4 - к канамицину, для 2 - к офлоксацину. Данные расхождения требуют дальнейшего анализа, в том числе с применением метода пропорций на жидких питательных средах.

Анализ данных о контактах с больным туберкулезом позволил установить, что только у 19/87 (22,9\%) пациентов был известен источник

Таблица 2. Лекарственная устойчивость изолятов МБТ разных генотипов, выделенных от больных туберкулезом в Новоуральском городском округе

Table 2. Drug resistance of МТВ isolates of various genotypes, isolated from tuberculosis patients in Novouralsk municipality

\begin{tabular}{|c|c|c|c|c|c|c|}
\hline \multirow{2}{*}{$\begin{array}{l}\text { Генетическая } \\
\text { группа }\end{array}$} & \multicolumn{2}{|c|}{ Количество повторов в локусах } & \multirow{2}{*}{$\begin{array}{c}\text { Общее количество } \\
\text { изолятов }\end{array}$} & \multicolumn{3}{|c|}{$\begin{array}{l}\text { Количество изолятов с разным спектром лекарственной } \\
\text { чувствительности }\end{array}$} \\
\hline & QUB26 & MIRU26 & & Лч & млу & шлу \\
\hline \multirow{5}{*}{ Beijing B0/W148 } & 6 & 7 & 2 & 0 & 2 & 1 \\
\hline & 2 & 7 & 9 & 0 & 9 & 2 \\
\hline & 7 & 8 & 1 & 0 & 1 & 0 \\
\hline & 7 & 6 & 7 & 0 & 6 & 0 \\
\hline & 7 & 7 & 32 & 0 & 30 & 3 \\
\hline \multirow{4}{*}{ Beijing other } & 6 & 5 & 3 & 0 & 3 & 0 \\
\hline & 8 & 5 & 10 & 5 & 4 & 0 \\
\hline & 7 & 5 & 1 & 0 & 1 & 0 \\
\hline & 7 & 7 & 3 & 0 & 3 & 0 \\
\hline Beijing всего & & & 68 & $5(7,3 \%)$ & $59(86,7 \%)$ & $6(8,8 \%)$ \\
\hline Смесь & - & - & 2 & 0 & 2 & 0 \\
\hline
\end{tabular}

Примечание: «-» не определяли; ЛЧ - МБТ с лекарственной чувствительностью; МЛУ - МБТ с множественной лекарственной чувствительностью; ШЛУ - с широкой лекарственной чувствительностью 
инфекции, 18/87 (18,3\%) пациентов ранее находились в местах лишения свободы, для 50/87 (58,8\%) источник инфицирования не установлен. Только $8(9,2 \%)$ пациентов имели постоянное место работы.

Из 19 пациентов с установленным контактом с больным туберкулезом у 9 (47,4\%) были выделены изоляты МБТ группы non-Beijing, в то время как у 50 больных с неустановленным контактом доминировали изоляты группы Beijing $(86,0 \%), p<0,01$. Высокая доля изолятов Beijing (83,3\%) была получена от больных, пребывавших в местах лишения свободы, что ранее также отмечено в других работах [8].

Использование результатов генотипирования для анализа эпидемиологических данных из историй болезней в ряде случаев позволило подтвердить или опровергнуть предполагаемые пути инфицирования МБТ. Так, сполиготип SIT35 был установлен для изолятов МБТ в семейном контакте: сын (с ВИЧ-инфекцией) $\rightarrow$ отец. Еще для трех пациентов с данным сполиготипом МБТ имелись данные о семейном контакте, однако второй культуры в описанной выборке не было.

Два пациента, от которых были выделены изоляты со сполиготипом SIT 262, согласно данным из истории болезни, между собой не контактировали. Для них были указаны данные о контактах с другими пациентами, культуры которых имелись в выборке, однако они принадлежали к другим генотипам (Beijing B0/W148 и SIT35).

В другом кластере Beijing B0/W148 (7 QUB26, 6 MIRU26) (7 изолятов) 2 пациента были из семейного контакта, 2 - из исправительных колоний, у 3 - контакт не установлен.

Для самого многочисленного кластера Beijing B0/W148 (7 QUB26, 7 MIRU26), объединяющего 32 изолята, установлен 1 подтвержденный семейный контакт (сын с ВИЧ-инфекцией $\rightarrow$ отец) и 2 неподтвержденных случая, когда пациенты проживали в одном доме и контакт между ними был вполне возможен. Еще 11 человек ранее пребывали в местах лишения свободы.

Анализ историй болезни для поиска возможных эпидемических связей для 9 изолятов впервые выделенного нами кластера Beijing B0/W148 (2 QUB26, 7 MIRU26) показал, что у 8 из них данных о контактах между собой не было, в одном случае был зарегистрирован семейный контакт, однако второй культуры в выборке не было. Ранее был в исправительной колонии 1 человек. ВИЧ-позитивными были 6 из 9 пациентов, при этом для 2 из них был указан один возможный источник инфекции (который имел другой генотип - SIT35), возможно, они могли контактировать и между собой. Проживали в одном доме 2 пациента, еще 2 - в одной деревне. Высокий процент пациентов с ВИЧ-инфекцией, инфицированных этим вариантом возбудителя тубер- кулеза, позволяет предположить, что пути передачи микобактерий в данном случае могут быть связаны с наличием ВИЧ-инфекции (рис.).

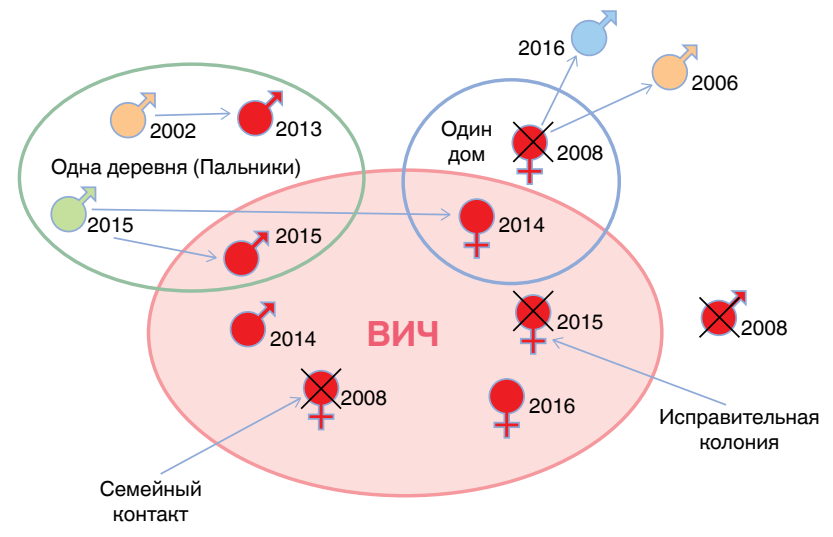

Рис. Анализ возможных путей распространения изолятов кластера Bеijing B0/W148 (2 QUB26, 7 MIRU26). Цифрами указан год постановки диагноза «туберкулеза». Красным цветом обозначены изоляты Beijing BO/W148 (2 QUB26, 7 MIRU26); зеленым - SIT35; оранжевым - Beijing B0/W148 (7 QUB26, 7 MIRU26); голубым - SIT252. Стрелками обозначены контакты согласно историям болезней. Перечеркнутье иконки - смерть пациента

Fig. Analysis of possible ways of transmission of isolates of Beijing BO/W148 cluster (2 QUB26, 7 MIRU26). Digits mark the year when tuberculosis was diagnosed. Isolates of Beijing B0/W148 (2 QUB26, 7 MIRU26) are highlighted in red; SIT35 - in green; Beijing B0/W148 (7 QUB26, 7 MIRU26) - in orange; SIT252 - in blue. The exposure is marked by arrows according to the case histories The crossed icons - lethal outcomes

\section{Заключение}

Молекулярно-генетическое исследование позволило установить, что на территории Новоуральского городского округа, имеющего ограниченную миграцию населения, идет преимущественное распространение наиболее трансмиссивных вариантов возбудителя, в частности, представителей кластера Beijing B0/W148, изначально обладающих МЛУ, что обусловливает высокий процент лекарственно-устойчивого туберкулеза среди вновь выявленных пациентов на этой территории. При этом на данной территории появляются и активно распространяются новые клональные варианты «успешных» штаммов, которые не встречаются в других регионах. Большое число лиц c ВИЧ-инфекцией на территории городского округа создает «резервуар» для распространения туберкулезной инфекции, в том числе с МЛУ возбудителя. Внедрение молекулярно-генетических методов, направленных на быстрое выявление возбудителя туберкулеза, определение его лекарственной устойчивости, может использоваться для мониторинга путей распространения туберкулеза.

Конфликт интересов. Авторы заявляют об отсутствии у них конфликта интересов.

Conflict of Interests. The authors state that they have no conflict of interests. 


\section{ЛИТЕРАТУРА}

1. Вязовая А. А., Мокроусов И. В., Журавлев В. Ю., Соловьева Н. С., Оттен Т. Ф., Маничева О. А., Вишневский Б. И., Нарвская О. В. Молекулярная характеристика мультирезистентных штаммов Mycobacterium tuberculosis, выделенных на Северо-Западе России // Молекулярная генетика, микробиология и вирусология. - 2016. - № 1. - С. 30-33.

2. Вязовая А. А., Соловьева Н. С., Сунчалина Т. В., Мокроусов И. В., Журавлев В. Ю., Нарвская О. В. Характеристика популяции Mycobacterium tuberculosis в Республике Карелия // Туб. и болезни легких. - 2016. - № 8. C. 48-53.

3. Жданова С. Н. Молекулярно-эпидемиологическое исследование распространения основных генотипов возбудителя туберкулеза в Северной Азии: Дис. ... д-ра мед. наук. - Иркутск, 2018. - 276 с.

4. Киселев В. Г., Пичугин В. В. К истории закрытых административных территориальных образований атомной отрасли [Электронный ресурс] // Proatom.ru. - 2011 URL: http://www.proatom.ru/modules.php?name=News \&file=article\&sid=3223 (дата обращения 21.09.2018)

5. Материалы для государственного доклада «О состоянии санитарноэпидемиологического благополучия населения Новоуральского городского округа в 2017 году» [Электронный ресурс] // fmbaros.ru-2018 URL: http://fmbaros.ru/Public/Ru/mru31/sancondition (дата обращения 21.09.2018)

6. Михайлищева М. С. Лекарственная устойчивость Mycobacterium tuberculosis у впервые выявленных больных в Свердловской области: Дис. ... магистра биологии. Уральский федеральный университет, Екатеринбург, 2018. - 44 с

7. Новоуральский городской округ. Официальный сайт правительства Свердловской области [Электронный ресурc] URL: http://www. midural.ru/100034/100089/mu_leaders/document2400/ (дата обращения 21.09.2018)

8. Огарков О. Б., Жданова С. Н., Зарбуев А. Н., Бадлеева М. В., Унтанова Л. С., Темирбаева И. В., Лац А. А., Савилов Е. Д. Полиморфизм Mycobacterium tuberculosis, выделенных от больных туберкулезом в пенитенциарной системе Бурятии: высокая распространенность генотипа Пекин // Сибирский мед. журнал. - 2012. - № 6. - С. 54-57.

9. Панов Г. А. Биологические свойства и эпидемиологическая значимость Mycobacterium tuberculosis, выделенных от больных с сочетанной патологией (туберкулез/ВИЧ): Дис. ... канд. мед. наук. - М., 2017.

10. Умпелева Т. В., Вязовая А. А., Еремеева Н. И., Кравченко М. А., Нарвская О. В., Скорняков С. Н. Генетические особенности возбудителя туберкулеза в Уральском федеральном округе России // Туб. и болезни легких. - 2016. - Т. 94, № 8. - С. 60-64.

11. Федеральные клинические рекомендации по организации и проведению микробиологической и молекулярно-генетической диагностики тубер кулеза, Москва. - 2015. - 36 с.

12. Mokrousov I., Narvskaya O., Vyazovaya A., Otten T., Jiao W., Gomes L., Suffys P. Shen A., Vishnevsky B. Russian "Successful” Clone B0/W148 of Mycobacterium tuberculosis Beijing Genotype: a Multiplex PCR Assay for Rapid Detection and Global Screening // J. Clin Microbiol. - 2012. - № 50 (11). - P. 3757-3759.

\section{ДЛЯ КОРРЕСПОНДЕНЦИИ:}

ФГБУ «Национальный медицинский исследовательский центр фтизиопульмонологии и инфекционных заболеваний» МЗ РФ,

620039, г. Екатеринбург, 22 Партсъезда, Ә. 50

Тел.: 8 (343) 333-44-66.

\section{Умпелева Татьяна Валерьевна}

кандидат биологических наук стариий научный сотрудник.

E-mail:tumpeleva@ya.ru

\section{REFERENCES}

1. Vyazovaya A.A., Mokrousov I.V., Zhuravlev V.Yu., Solovieva N.S., Otten T.F., Manicheva O.A., Vishnevskiy B.I., Narvskaya O.V. Molecular description of multiple drug resistant strains of Mycobacterium tuberculosis, isolated in North-West Russia. Molekulyarnaya Genetika, Mikrobiologiya $i$ Virusologiya, 2016, no. 1, pp. 30-33. (In Russ.)

2. Vyazovaya A.A., Solovieva N.S., Sunchalina T.V., Mokrousov I.V. Zhuravlev V. Yu., Narvskaya O.V. Characteristics of Mycobacterium tuberculosis population in Kareliya Republic. Tuberculosis and Lung Diseases, 2016, no. 8, pp. 48-53. (In Russ.)

3. Zhdanova S.N. Molekulyarno-epidemiologicheskoe issledovanie rasprostraneniya osnovnykh genotipov vozbuditelya tuberkuleza $v$ Severnoy Azii. Dis. dokt. med. nauk. [The molecular epidemiological study of transmission of main genotypes of M. tuberculosis in the Northern Asia. Doct. Diss.]. Irkutsk, 2018, 276 p.

4. Kiselev V.G., Pichugin V.V. Kistorii zakrytykh administrativnykh territorialnykh obrazovaniy atomnoy otrasli. [About the history of closed municipalities within nuclear industry]. (Epub.), Proatom.ru. 2011, Available: http://www.proatom. $\mathrm{ru} /$ modules.php? name $=$ News $\&$ file $=$ article $\&$ sid $=3223$ (Accessed: 21.09 .2018 )

5. Materialy dlya gosudarstvennogo doklada «O sostoyanii sanitarno-epidemiologicheskogo blagopoluchiya naseleniya Novouralskogo gorodskogo okruga $v 2017$ godu». [Materials for the state report on the sanitary and epidemiological well-being of population of Novouralsk municipality in 2017]. (Epub.), fmbaros.ru2018, Available: http://fmbaros.ru/Public/Ru/mru31/sancondition (Accessed 21.09.2018).

6. Mikhaylischeva M.S. Lekarstvennaya ustojchivost Mycobacterium tuberculosis u vpervye vyyavlennykh bolnykh $v$ Sverdlovskoy oblasti. Diss. magistra biologii. [Drug resistance of tuberculous mycobacteria in new cases of Sverdlovsk Region. Thesis of Master of Biology]. Ural Federal University, Yekaterinburg, 2018, 44 p.

7. Novouralsk municipality. Official website of Sverdlovsk Regional Government. (Epub.) Available: http://www.midural.ru/100034/100089/mu leaders/document2400/ (Accessed 21.09.2018). (In Russ.)

8. Ogarkov O.B., Zhdanova S.N., Zarbuev A.N., Badleeva M.V., Untanova L.S., Temirbaeva I.V., Lats A.A., Savilov E.D.Polymorphism of Mycobacerium tuberculosis, isolated from tuberculosis patients in the penitentiary system of Buryatia: high prevalence of Beijing strain. Sibirskiy Med. Journal, 2012, no. 6, pp. 54-57. (In Russ.)

9. Panov G.A. Biologicheskie svoystva $i$ epidemiologicheskaya znachimost Mycobacterium tuberculosis, vydelennykh ot bolnykh s sochetannoy patologiey (tuberkulez/VICH).Dis. kand. med. nauk. [Biological properties and epidemiological value of Mycobacterium tuberculosis isolated in the co-infected patients (tuberculosis/HIV). Cand. Diss.]. Moscow, 2017.

10. Umpeleva T.V., Vyazovaya A.A., Eremeeva N.I., Kravchenko M.A., Narvskaya O.V., Skornyakov S.N. Specific genetic features of Mycobacterium tuberculosis in Ural Federal District of Russia. Tuberculosis and Lung Diseases, 2016, vol. 94, no. 8, pp. 60-64. (In Russ.)

11. Federalnye klinicheskie rekomendatsii po organizatsii $i$ provedeniyu mikrobiologicheskoy i molekulyarno-geneticheskoy diagnostiki tuberkuleza. [Federal clinical recommendations on organization and implementation of microbiological and molecular-genetic diagnostics of tuberculosis]. 2015, 36 p.

12. Mokrousov I., Narvskaya O., Vyazovaya A., Otten T., Jiao W., Gomes L., Suffys P., Shen A., Vishnevsky B. Russian "Successful" Clone B0/W148 of Mycobacterium tuberculosis Beijing Genotype: a Multiplex PCR Assay for Rapid Detection and Global Screening. J. Clin Microbiol., 2012, no. 50 (11), pp. 3757-3759.

\section{FOR CORRESPONDENCE:}

National Medical Research Center

of Phthisiopulmonology and Infectious Diseases

50, XXII Parts"ezda St.,

Yekaterinburg, 620039.

Phone: +7 (343) 333-44-66.

Tatiana V. Umpeleva

Candidate of Biological Sciences,

Senior Researcher.

Email: tumpeleva@ya.ru 


\section{Белоусова Ксения Валерьевна}

кандидат биологических наук,

старший научный сотрудник.

E-mail:kbobrovskaya@mail.ru

\section{Голубева Людмила Андреевна}

младиий научный сотрудник.

E-mail: golubeva.luda2010@yandex.ru

\section{Еремеева Наталья Ивановна}

кандидат биологических наук,

старший научный сотрудник.

E-mail:eremeevani@ya.ru

\section{Вахрушева Диана Владимировна}

кандидат биологических наук, ученый секретарь.

E-mail: vakhrusheva@urniif.ru

\section{Морозова Ирина Михайловна}

ФГБУЗ «ЦМСЧ № 31 ФМБА России»,

заведующая туберкулезным отделением, врач-фтизиатр,

главный внештатный спеииалист-фтизиатр

Новоуральского городского округа.

624130, Свердловская обл., г. Новоуральск, Садовая ул., д. $2 a$.

E-mail:docirina2008@yandex.ru

\section{Ksenia V. Belousova}

Candidate of Biological Sciences,

Senior Researcher.

Email:kbobrovskaya@mail.ru

\section{Lyudmila A. Golubeva}

Junior Researcher.

Email: golubeva.luda2010@yandex.ru

\section{Natalya I. Eremeeva}

Candidate of Biological Sciences,

Senior Researcher.

Email:eremeevani@ya.ru

Diana V. Vakhrusheva

Candidate of Biological Sciences, Academic Secretary.

Email:vakhrusheva@urniif.ru

\section{Irina M. Morozova}

Central Medical Sanitary Unit no. 31

by the Russian Federal Medical Biological Agency,

Head of Tuberculosis Department, Phthisiologist,

Chief Visiting Phthisiologist of Novouralsk Municipality 2a, Sadovaya St., Novouralsk, Sverdlovsk Region, 624130

Email: docirina2008@yandex.ru 